\title{
O PAPEL DO DESIGN(ER) NAS POLÍTICAS PÚBLICAS CULTURAIS
}

\author{
Eduardo Cardoso \\ Universidade Federal do Rio Grande do Sul - UFRGS \\ eduardo.cardoso@ufrgs.br \\ Maria do Carmo Gonçalves Curtis \\ Universidade Federal do Rio Grande do Sul - UFRGS \\ maria.curtis@ufrgs.br \\ Tânia Luisa Koltermann da Silva \\ Universidade Federal do Rio Grande do Sul - UFRGS \\ tania.silva@ufrgs.br \\ Liane Roldo \\ Universidade Federal do Rio Grande do Sul - UFRGS \\ liane.roldo@ufrgs.br \\ Júlio Carlos de Souza Van Der Linden \\ Universidade Federal do Rio Grande do Sul - UFRGS \\ julio.linden@ufrgs.br
}

\begin{abstract}
Resumo: $O$ presente artigo apresenta conceitos gerais para 0 embasamento teórico relativo aos fatores humanos aplicados ao design, em especial ao nível político e suas inter-relações. Desta forma, abordamse também questões relativas às Políticas Públicas Culturais e sua contextualização histórica frente à inserção do design neste campo. Assim, este trabalho visa refletir sobre o papel do design(er) na discussão, formulação e implantação de políticas públicas culturais que considerem a sua relação com o design.
\end{abstract}

Palavras-chave: Fatores Humanos, Design Social, Politicas Públicas Culturais.

Abstract: This paper presents general concepts for the theoretical background on human factors applied to the design, especially at the political level and their interrelationships. Thus, also addressing issues relating to Cultural Public Policies and its historical contextualization front insert design in this field. Thus, this paper aims to reflect on the role of design(er) in the discussion, formulation and implementation of cultural policies that consider their relationship with the design. 
Keywords: Human Factors, Social Design, Cultural Public Policies.

\section{INTRODUÇÃo}

Primeiro faz-se necessário a apresentação de alguns conceitos gerais acerca da temática do trabalho para posterior aprofundamento. Para iniciar uma compreensão dos fatores humanos, a partir de uma perspectiva mais ampla e sistêmica, buscou-se embasamento no livro The Human Factor: revolutionizing the way people live with technology, de Kim Vicente (2003). Para tratar sobre Políticas Públicas e a inserção do design, assim como sobre práticas colaborativas nesta área, referencia-se Stefano Maffei, Marzia Mortati e Beatrice Villari (2012) em seu artigo denominado Making/Design policies together. Acerca de Políticas Públicas e Políticas Culturais, buscou-se amparo nas publicações de Lia Calabre (2007), José Teixeira Coelho Neto (1997) e Wagner Braga Batista (2010, 2012, 2012A, 2013), atualmente, porta-voz da inserção da área do design na formulação e implementação de Políticas Públicas Culturais no cenário nacional.

\subsection{Fatores Humanos}

Conforme descrito anteriormente, o presente artigo estrutura-se a partir das referências de Kim Vicente (2004), que, baseado na abordagem sistêmica, apresenta uma aproximação humano-tecnológica para o design de tecnologia. Nesta concepção, abandonam-se as abordagens puramente humanísticas ou mecanicistas. Nela, o design deve começar pela compreensão da necessidade humana ou societária para então modelar a tecnologia a fim de refletir os fatores humanos envolvidos. Para tanto, Vicente (2004) apresenta a Escada Humano-tecnológica como um mapa conceitual desta abordagem (Figura 01). A partir desta estrutura, deve-se começar o entendimento dos fatores humanos envolvidos pela base da mesma, ou seja, pelos fatores físicos, para então começar a subir em direção aos outros níveis, como o trabalho em equipe, às organizações e os sistemas políticos. 


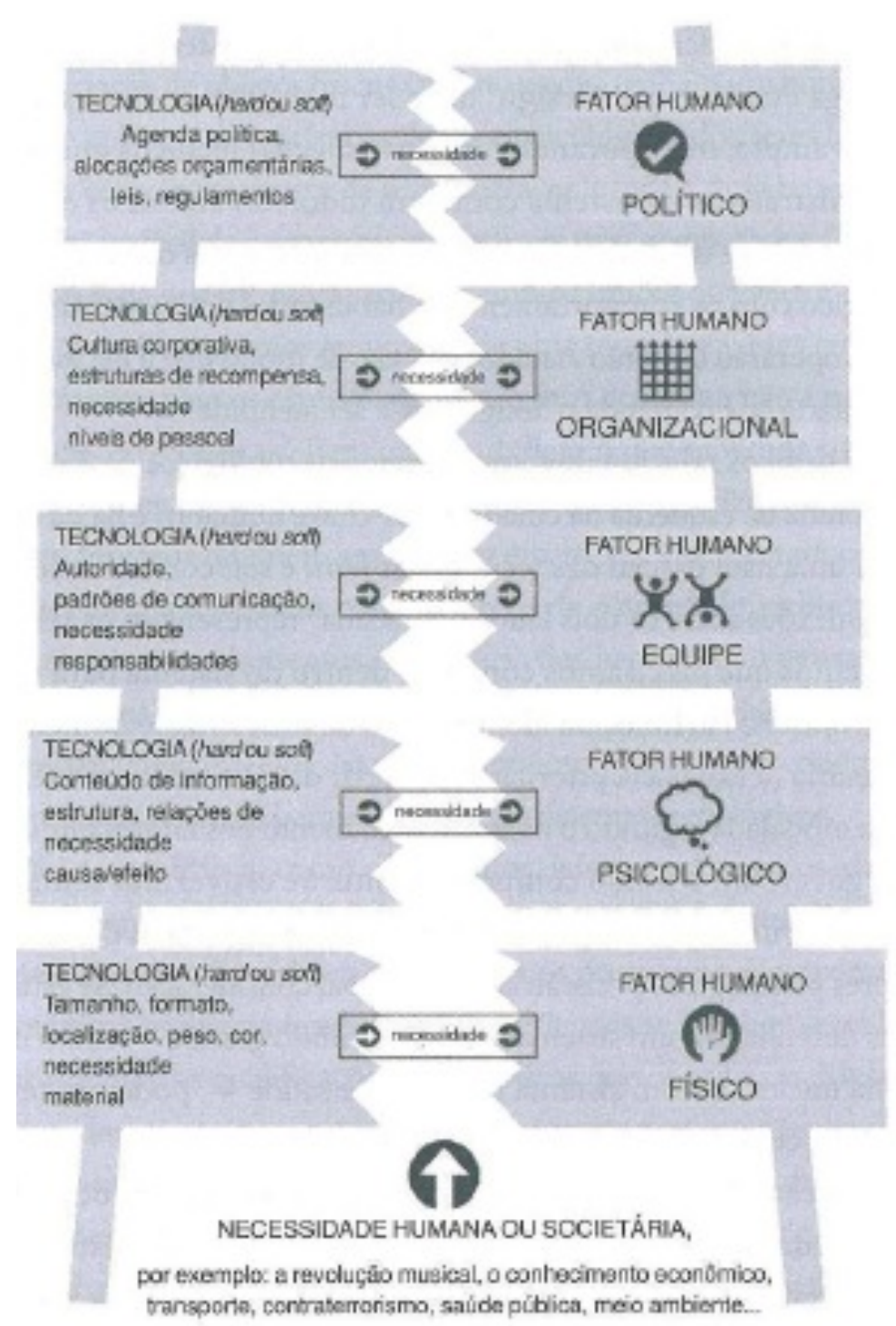

Figura 01: Escada Humano-tecnológica. Fonte: Vicente (2004).

Neste primeiro nível da escada, os fatores físicos são considerados, tais como tamanho, forma, etc. Já no nível seguinte, o psicológico, deve-se considerar a capacidade humana de memorização, as expectativas intuitivas de dar sentido ao mundo, a habilidade de fazer cálculos mentais complexos e capacidade apurada de reconhecimento de padrões quando se projetam sistemas tecnológicos. Os níveis físico e psicológico constituem um bom trabalho relativo à caracterização dos indivíduos, mas estes não trabalham/atuam isoladamente, assim, o terceiro nível apresenta os fatores relativos às dinâmicas de grupo, tais como comunicação, motivação e bom relacionamento, em busca de um efeito sinergético. Todavia, equipes não existem isoladas, em geral fazem parte de uma unidade maior, como unidades organizacionais, nível onde se introduz mais um conjunto de características humanas: visão e liderança, incentivos e estímulos, e o modo como a informação flui gerando impacto sobre o comportamento organizacional. Salienta-se que as decisões tomadas nos níveis mais altos, como o organizacional, podem influenciar os outros níveis, como as questões relativas à realização de tarefas, fadiga, sobrecarga. Por fim, o nível mais elevado da escada é o político. Vicente (2005) destaca que "nossa compreensão da natureza humana no nível político não é tão sofisticada ou tão completa quanto a dos níveis 
físico e psicológico, porque os fenômenos a serem explicados são muito mais complexos". Assim, quando trata-se dos níveis mais altos, não foca-se exclusivamente no produto ou "coisa"em questão e sim em padrões ou conceitos como relação de autoridade, políticas de pessoal, leis e regulamentos. "Objetos políticos, como orçamentos, leis e regulamentos, deveriam ser considerados parte do sistema tecnológico porque afetam o modo como funcionarão os objetos físicos do sistema", podendo assim ser considerado um dos níveis mais importantes, pois exerce influência nos demais (VICENTE, 2005). Em síntese, a argumentação do autor assinala a importância de compreender os sistemas políticos e como estes podem afetar e interagir com design(er).

\title{
2. POLÍTICA PÚBLICA CULTURAL
}

Partindo do conceito de política pública, é importante abordar a relação entre Estado e Sociedade. Segundo Pereira-Bresser (1995), o Estado, enquanto estrutura política e organizacional, se sobrepõe à sociedade ao mesmo tempo em que faz parte dela. Assim, esta relação, Estado e Sociedade, "é o que conduz as ações no sentido de construir consensos e controlar conflito de interesse" (MENEZ, p. 11, 2011). Para Schmitter (1984, apud Menez, 2011), esses conflitos são administrados "pacificamente" pela política.

\begin{abstract}
A relação entre Estado e Sociedade se dá através da consecução de um sistema de decisões que se traduz em ações ou omissões, preventivas ou corretivas, destinadas a modificar ou manter a realidade de um ou vários setores da vida social, através da determinação de fins últimos, objetivos e estratégias de atuação, ao que se denomina política pública.
\end{abstract}

(MEZEZ, 2011 apud SARAIVA, 2001, P.66)

Segundo Menez (2011), pode-se ter um melhor entendimento do conceito de Política Pública quando comparamos os dois termos em inglês: politics e policy, sendo o primeiro relativo às atividades políticas e o segundo ligado a desenvolvimento de políticas públicas abrangendo a formulação de propostas, tomada de decisão e implantação de políticas pelas organizações públicas. Porém, estão entrelaçados e se influenciam, pois políticas públicas são resultantes das atividades políticas.

Para Rua (2009, apud Menez, 2011), o ciclo de políticas públicas é dividido nas seguintes fases: (1) formação de agenda; (2)formação de alternativas e tomada de decisão; (3) implantação; (4) avaliação e monitoramento. Assim, as políticas públicas devem ser elaboradas com base em preceitos que garantam respostas efetivas às necessidades dos atores sociais, considerando a continuidade e a permanência dos processos, sustentados em sua avaliação e monitoramento. Além disto, devem ser capazes de se adaptar às mudanças e serem coerentes com as demais políticas governamentais, voltando-se aos interesses que as originaram. Assim, são consolidadas e apresentadas por meio dos Planos de Governo que apresentam as estratégias, objetivos, programas e orientação política visando apresentar "o que", "quando"e "como" as ações do governo serão tratadas.

Para Maffei, Mortati e Villari (2012), considera-se política a maneira pela qual um sistema político (política + governança) compartilha um conjunto de regras, atividades e processos necessários para, segundo o conceito de design de Simon, "transformação de condições existentes para preferenciais". Os autores distinguem três níveis: políticas, programas e iniciativas. Nas políticas têm-se as regras, atividades 
e processos que traduzem uma visão política em programas e ações para cumprimento dos objetivos do Modelo de Gestão estabelecido. Os programas são os objetivos a serem atendidos e as atividades a serem desenvolvidas para cumprir o Modelo de Gestão. As iniciativas são os processos e ações empreendidas para atender as políticas e programas (MAFFEI, MORTATI e VILLARI, 2012).

Os mesmos autores destacam ainda que as Políticas Públicas não devem ser feitas somente por políticos, mas por todos os atores que formam a sociedade, entendendo assim como práticas colaborativas podem melhorar e apoiar a formulação de políticas em diferentes níveis. Desta forma, Maffei, Mortati e Villari (2012) definem três graus de envolvimento na relação dos cidadãos com o governo, desde o mais passivo ao mais ativo: informativo - relação unilateral quando o governo troca dados, mas deixa-os fora do processo de decisão; Consultivo - relação mútua quando o governo não só informa, mas pergunta e solicita retorno para as decisões; Participativo - relação recíproca quando o governo envolve os cidadãos no ciclo de formulação das políticas, uma vez que são suficientemente competentes para sugerir soluções e contribuir com o debate.

Já Política Cultural pode ser entendida como um conjunto de iniciativas e medidas de apoio institucional sistemático desenvolvido pela administração pública ou instituições civis, grupos comunitários e empresas privadas na perspectiva de orientar o reconhecimento, a proteção e o estímulo ao desenvolvimento simbólico material e imaterial de determinada sociedade ou grupo social (COELHO NETO, 1997).

Em uma ação do poder público, uma política cultural se traduz por operações, princípios e procedimentos administrativos e orçamentários com características de instruções e diretrizes, tanto de ação direta quanto de fomento, assim como de meios regulatórios apropriados ao setor - normas jurídicas que regem as relações entre os sujeitos e os objetos culturais - em modelos e rearranjos ideológicos e econômicos com vistas à conservação de patrimônio e a democratização da cultura, desde o consumo e a produção de bens e serviços até a participação e a criação de processos culturais, em modalidades com objetivos diferentes - excludentes ou cumulativos - e por vezes incompatíveis.

A partir de diferentes modos de compreensão da significação dessas iniciativas e, por conseguinte, pelos respectivos modos de proposição e agenciamento das mesmas é possível verificar o comprometimento do Estado com a cultura nos diferentes contextos sociais, no que se refere à democratização do acesso e da fruição e a diversidade da oferta de bens e serviços culturais.

\section{CONTEXTUALIZAÇÃO HISTÓRICA DAS POLÍTICAS CULTURAIS NO BRASIL}

No contexto brasileiro, a relação existente entre Estado e a cultura é longa, mas o entendimento da necessidade de planejamento de políticas para o setor, através de ações com maior duração, é instaurado somente a partir do século XX, em especial na década de 1930. As pesquisas mais recentes indicam que, nos anos 1930 e 40, o assunto ainda não era tratado enquanto política cultural, o que se observa naquele período são ações isoladas, decorrentes de relações entre o campo da política, da cultura e da arte. Apenas no período pós-guerra, 1950, a cultura começa a receber uma atenção mais sistemática, enquanto ação global e organizada. Portanto, no caso brasileiro, a "institucionalização da política cultural é uma característica dos tempos atuais" (CABRALE, 2007). 
Na França, em 1959, foi criado o Ministério de Assuntos Culturais, instituição que contribui para a institucionalização do campo da cultura, representando importante referência para muitos países ocidentais. Ao estabelecer esse nexo entre a institucionalização do campo da cultura na França e o caso brasileiro, interessa aqui destacar que os estudos de política cultural esclarecem muito a respeito de "uma espécie de história da ideologia cultural do Estado" (Urfalino, 2004 apud Cabrale, 2007). Sobretudo, se considerarmos a longa relação que Brasil e França estabelecem no campo da arte e cultura, o qual pode datar desde a vinda da Missão Artística, em 1816.

A seguir (Quadro 01) se apresenta o percurso histórico da relação Estado e cultura no contexto brasileiro de meados do século XX até a atualidade para elucidar fatos importantes no processo que vai articulando os campos da cultura e da política.

Quadro 01: Percurso histórico da relação Estado e Cultura no contexto brasileiro.

\begin{tabular}{|c|c|}
\hline $\begin{array}{l}1930 \\
1945\end{array}$ & Período do governo de Getúlio Vargas, medidas para institucionalizar o setor cultural; \\
\hline 1937 & Criação do Serviço do Patrimônio Histórico e Artístico Nacional (SPHAN); \\
\hline 1938 & Criado o primeiro Conselho Nacional de Cultura (CNC); \\
\hline $\begin{array}{l}1945 \\
1964\end{array}$ & Período de grande desenvolvimento cultural na iniciativa privada; \\
\hline 1945 & $\begin{array}{l}\text { Encerra a guerra, retorno da produção de aparelhos de rádio e equipamentos de transmissão; o } \\
\text { número de emissoras de rádio cresce } 100 \% \text {, na década de 1940; }\end{array}$ \\
\hline 1950 & Inaugurada a primeira emissora de TV no Brasil, por Assis Chateaubriand, a TV Tupi; \\
\hline 1953 & $\begin{array}{l}\text { Ministério da Educação e Saúde foi desmembrado em Ministério da Saúde (MS) e o da Educação } \\
\text { e Cultura (MEC); }\end{array}$ \\
\hline 1961 & $\begin{array}{l}\text { Jânio Quadros recriou o Conselho Nacional de Cultura, subordinado diretamente a presidência } \\
\text { da república; }\end{array}$ \\
\hline 1962 & CNC retorna a subordinação ao MEC; \\
\hline 1964 & $\begin{array}{l}\text { Governo militar do Estado retoma o projeto de maior institucionalização do campo da produção } \\
\text { artístico-cultural; }\end{array}$ \\
\hline 1966 & $\begin{array}{l}\text { Criado o Conselho Federal de Cultura (CFC), com membros indicados pelo Presidente da } \\
\text { República; os planos de cultura apresentados visavam a recuperação de instituições nacionais - } \\
\text { Biblioteca Nacional, o Museu Nacional de Belas Artes, o Instituto Nacional do Livro, etc; o CFC } \\
\text { era incumbido de analisar pedidos de verba ao MEC, instituindo uma política de apoio a uma } \\
\text { série de ações, papel exercido até 1974; }\end{array}$ \\
\hline $\begin{array}{l}1970 \\
1979\end{array}$ & $\begin{array}{l}\text { Processo de institucionalização do campo da cultura nas áreas de atuação do governo, em } \\
\text { nível federal, estadual e municipal; }\end{array}$ \\
\hline 1970 & Criado o Departamento de Assuntos Culturais, DAC, subordinado ao MEC; \\
\hline 1973 & $\begin{array}{l}\text { Lançado O Plano de Ação Cultural (PAC), abrangia o setor de patrimônio, atividades artísticas e } \\
\text { culturais, capacitação de pessoal; sua meta era a implementação de um calendário de eventos } \\
\text { culturais patrocinados pelo Estado, com espetáculos nas áreas de música, teatro, circo, folclore } \\
\text { e cinema com circulação pelas diversas regiões do país; }\end{array}$ \\
\hline $\begin{array}{l}1974 \\
1978\end{array}$ & $\begin{array}{l}\text { Governo Geisel, na gestão do Ministro Ney Braga, período de fortalecimento da área da } \\
\text { cultura, cria órgãos estatais que atuam em novas áreas: Conselho Nacional de Direito Autoral } \\
\text { (CNDA), o Conselho Nacional de Cinema, a Campanha de Defesa do Folclore Brasileiro e a } \\
\text { Fundação Nacional de Arte (FUNARTE); }\end{array}$ \\
\hline 1976 & $\begin{array}{l}\text { Criação do Centro Nacional de Referência Nacional (CNRC), por um convênio do Ministério da } \\
\text { Indústria e Comércio e o governo do Distrito Federal, prevendo a formação de um grupo de } \\
\text { trabalho, sob a direção de Aloísio Magalhães, para estudar alguns aspectos e especificidades da } \\
\text { cultura e do produto cultural brasileiro; oficializado por um convênio entre a Sec. de } \\
\text { Planejamento, o Ministério de Relações Exteriores, o Ministério da Indústria e do Comércio, a } \\
\text { Universidade de Brasília e a Fundação Cultural do Distrito Federal; }\end{array}$ \\
\hline 1979 & $\begin{array}{l}\text { Aloísio Magalhães criou no âmbito do MEC a Fundação Nacional Pró-Memória, ampliando o } \\
\text { trabalho do CNRC; }\end{array}$ \\
\hline 1979 & $\begin{array}{l}\text { O Departamento de Assuntos Culturais foi substituído pela Secretaria de Assuntos Culturais, } \\
\text { assinalando uma divisão da atuação em duas vertentes: patrimonial e outra de produção, }\end{array}$ \\
\hline
\end{tabular}




\begin{tabular}{|c|c|}
\hline & circulação e consumo da cultura; \\
\hline 1981 & Aloísio Magalhães assume a direção da Secretaria de Cultura; \\
\hline 1985 & Criado o Ministério da Cultura; \\
\hline 1986 & $\begin{array}{l}\text { Criada a Lei Sarney de incentivos fiscais, cujo objetivo era criar novas fontes de recursos para } \\
\text { impulsionar o campo de produção artístico-cultural; }\end{array}$ \\
\hline 1990 & Inicio do processo de uma nova política cultural voltada para as leis de mercado; \\
\hline 1990 & O Ministério da Cultura foi extinto no governo de Fernando Collor, a Lei Sarney foi revogada; \\
\hline 1991 & $\begin{array}{l}\text { A Lei Rouanet começa a injetar recursos financeiros no setor cultural através do mecanismo de } \\
\text { renúncia fiscal; }\end{array}$ \\
\hline 1992 & Ministério da Cultura é recriado, sob governo de Itamar Franco; \\
\hline 2002 & A partir do mandato de governo Lula, inicia processo de melhor distribuição de recursos; \\
\hline 2003 & $\begin{array}{l}\text { Gilberto Gil é nomeado Ministro da Cultura no governo Lula. Busca por melhor distribuição de } \\
\text { recursos no setor cultural. Inicio do diálogo entre o MinC e a sociedade civil. }\end{array}$ \\
\hline
\end{tabular}

Fonte: Adaptado de CALABRE, Lia, 2007.

O Quadro 01 apresenta uma síntese do percurso da relação Estado e cultura no contexto histórico brasileiro desde os anos 1930 até a contemporaneidade. Por meio dos dados apresentados é possível verificar que a trajetória das Políticas Públicas Culturais sofre influência direta dos respectivos sistemas de governo. Salienta-se o momento presente como um período em que o governo busca formular políticas públicas através de preceitos que garantem respostas mais efetivas às necessidades dos atores sociais. Nesse sentido, consideramos as Conferências Nacionais de Cultura como indicadores positivos desse processo mais participativo, as quais serão abordadas no próximo item.

\section{O DESIGN(ER) E AS POLÍTICAS PÚBLICAS CULTURAIS}

Ao tratar a respeito do tema design e políticas públicas Wagner Braga Batista (2010) pondera que na área do design há resistência à participação política, o que repercute de modo negativo, pois dificulta identificar as especificidades do campo de intervenções do design, assim como inserir o design no corpo de proposições mais amplas, abrangentes e integradoras característico das políticas públicas. "Resistir à participação política impede o diálogo do design e sua relação com outros setores culturais".

Entretanto, o cenário atual tem favorecido mudanças positivas na relação do design com outros setores culturais. $O$ autor salienta que a realização de Conferências Nacionais com proposição de políticas públicas no Brasil começam a reverter metodologias que costumavam confinar formulações políticas em gabinetes, restringindo a decisão de prioridades culturais a tecnocratas com pouca (ou nenhuma) inserção nos campos de atividade de suas deliberações.

A transferência de responsabilidade da elaboração e da implementação de políticas sociais para agentes culturais é um principio promissor, afirma Batista, porque políticas públicas desenvolvidas a partir de expectativas e necessidades dos atores diretos revelam-se mais coerentes, eficientes e promovem maior adesão do ponto de vista social.

Dentre as novas metodologias no campo da cultura e sua repercussão no campo do design, Batista (2010) examina especialmente a inserção do design na II Conferência Nacional de Cultura realizada em março de 2010 e acompanha o processo de inserção do Colegiado Setorial de Design em etapa preliminar da III CNC, realizada em novembro de 2013. 
As Conferências Nacionais têm promovido o planejamento participativo, visando a formulação de diretrizes para políticas públicas nos seus respectivos campos de abrangência. No cenário nacional, o processo de participação popular na formulação de políticas públicas é recente. Conforme Avritzer (2010 apud Batista 2010) 28 segmentos organizados participaram de conferências nacionais pela primeira vez desde 2002. "Ainda precoces, o planejamento participativo e as conferências nacionais convertem-se em laboratórios para o aprendizado democrático exercido por meio da formulação de políticas públicas."

Para maior clareza e compreensão desse recente processo democrático que começa a se articular na relação Estado e Cultura, apresenta-se o Quadro 02 que expõe as datas e fatos mais relevantes a partir da perspectiva do design.

Quadro 02: Percurso da relação Estado e Cultura na perspectiva do design.

\begin{tabular}{|ll|}
\hline 2005 & I CNC, I Conferência Nacional de Cultura; \\
\hline 2009 & $\begin{array}{l}\text { Integração à agenda do Ministério de Cultura dos setores de design, arquitetura e urbanismo, } \\
\text { artesanato, moda e arte digital; }\end{array}$ \\
\hline 2010 & I Pré- conferência Setorial de Design ; II Conferência Nacional de Cultura; \\
\hline 2012 & I Colegiado Setorial de Design; \\
\hline 2013 & III Conferência Nacional de Cultura. \\
\hline
\end{tabular}

Fonte: Elaborado pelos autores.

A II Conferência Nacional de Cultura/ 2010 foi precedida de um processo de discussão em 26 estados e no Distrito Federal, através de plenárias de 19 setores de atividades artísticas e culturais, integrantes do MinC. Cabe destacar que o design foi incorporado à agenda do Ministério da Cultura desde 2009, junto com os setores de arquitetura e urbanismo, artesanato, moda e arte digital. Assim, a II CNC/ 2010 marca o início das relações institucionais do Ministério da Cultura com as áreas da moda, arquitetura e design. As produções dessas áreas passam a ser consideradas manifestações da identidade brasileira e por isso devem ser contempladas nas ações do próprio MinC e de outras instituições que fomentam e apoiam a cultura.

Etapa preliminar da CNC, a I Pré- conferência Setorial de Design, realizada em fevereiro de 2010, no Rio de Janeiro, resultou na elaboração de cinco diretrizes norteadoras para viabilizar o design no Plano Nacional de Cultura; na indicação de dez delegados e um observador para a IICNC; na escolha de três nomes para a lista tríplice, para a nomeação de integrantes do Conselho Nacional de Políticas Culturais. A intenção das diretrizes é valorizar, reconhecer, divulgar e fomentar o design. São elas: (1) Produção simbólica e diversidade cultural; (2)Cultura, cidade e cidadania; (3)Cultura e desenvolvimento sustentável; (4) Cultura e economia criativa; (5) Gestão e institucionalidade da cultura.

As Pré-conferências Setoriais de Cultura têm caráter mobilizador, reflexivo, propositivo e eletivo, são instâncias de articulação local e regional de agentes culturais de cada uma das áreas artísticas e de patrimônio envolvidas, sendo parte do processo da II Conferência Nacional de Cultura (II CNC). Os objetivos das Pré-conferências Setoriais de Cultura são promover o debate e a reflexão valorizando a complexidade e a diversificação de atividades em cada um dos campos setoriais. Assim como debater e encaminhar propostas para as políticas públicas de cultura e as políticas setoriais específicas para cada um dos segmentos envolvidos no processo, contribuindo na formulação dos Planos Nacionais Setoriais. 
Em análise da articulação do design no processo da IICNC/2010, Batista (2010) considera que sua representatividade foi deficiente, e atribui como causas dessa problemática a complexidade do setor, assim como as dificuldades de agregação e à "falta de uma cultura de participação coletiva". Mas, ele estima que tudo isso corresponde ao estágio inicial de um processo em andamento, que será revertido através do amadurecimento e da participação em futuros eventos.

Além disso, ao avaliar a relação do design e políticas públicas no Brasil, Batista (2010) identifica dois problemas: (1) a disjunção entre os interesses específicos do setor e as formulações gerais das políticas públicas; e (2) o equívoco existente entre políticas públicas e políticas de governo.

De acordo com o autor, para contemplar reivindicações do setor é preciso que o design se insira, do ponto de vista social, no contexto de políticas mais amplas, integradoras e consistentes. A despeito do design estar associado ao âmbito econômico, na produção e comercialização de produtos, ou vetor de ações culturais, sua viabilidade vincula-se à articulação e integração com outros segmentos no fomento de políticas sociais. Desse modo, argumenta Batista (2010), o design precisa ampliar sua perspectiva de intervenção ficar estrita ao mercado.

Quanto à confusão entre políticas públicas e políticas de governo, ele enfatiza que as primeiras são políticas de Estado, com continuidade respaldada pela lei, enquanto que as políticas de governo são contingenciais, alinhadas com projetos governamentais. Portanto, ao participar da formulação de estratégias e diretrizes para a cultura, o design começa a se inserir no escopo de políticas públicas, abrangentes, integradoras e duradouras.

Do ponto ponto de vista endógeno, o cerne da questão é que no campo do design existe uma postura que:

Reveste-se de um apoliticismo que não condiz com a visão socioeconômica
e a sensibilidade crítica que afirmamos mover nossas ações e projetos. Essa
postura se mostra refratária ao reconhecimento do pluralismo de ideias, de
interlocutores, da importância do diálogo e do convencimento. Procura se
manter e se cristalizar por meio de artifícios que constituem a negação da
convivência democrática. Sua visão é elitista e cupulista, portanto
excludente. Seus mecanismos de subsistência impõem a formação de
grupos e de guetos de autolegitimação que tendem a discriminar e isolar
vozes e ações discordantes. Não admitem o contraditório, recusando-se a
aceitar os processos dialógicos por meio dos quais a vontade majoritária e a
democracia se afirmam. A priori nega a importância da participação de
designers e desenhistas industriais em esferas da vida social que influem
decisivamente em suas atividades.

(BATISTA, 2010)

No âmbito das políticas culturais, abrangentes e integradoras, o design precisa enfrentar novos desafios, a fim de conquistar um espaço próprio e afirmar sua identidade. Um caminho possível, indica o autor, é reunir-se com outros setores culturais com objetivos parecidos, em proposições transversais, em ações cooperativas e fins sociais.

Na continuidade do processo democrático da relação entre Estado e cultura cabe destacar que em setembro de 2013, as Conferências Estaduais de Cultura já elegeram 356 delegados para representar seus estados na III CNC, realizada em novembro de 2013, em Brasília. A sociedade civil, gestores e produtores foram representados pelos delegados no evento, que teve como tema principal Uma Política 
de Estado Para a Cultura: Desafios do Sistema Nacional de Cultura. Nesta edição a Conferência Nacional teve quatro eixos que trataram de temas como: Implementação do Sistema Nacional de Cultura no País; Produção Simbólica e Diversidade Cultural; Cidadania e Direitos Culturais; e Cultura e Desenvolvimento Econômico Sustentável. Os 356 delegados são dos estados que já realizaram as conferências e computaram seus dados.

Na perspectiva do design verifica-se avanços na participação do processo. Em julho de 2013 realizou-se a I Reunião do Colegiado Setorial de Design, em Brasília. Constituído em dezembro de 2012, o Colegiado Setorial de Design dá continuidade ao processo de integração do design ao Ministério da Cultura, em 2009. O Colegiado Setorial é organismo subsidiário do Conselho Nacional de Políticas Culturais, CNPC, responsável pela proposição de diretrizes políticas setoriais que, uma vez aprovadas no Conselho Nacional de Cultura, CNC, fornecerão estofo à política cultural.

Os colegiados setoriais têm como atribuição a escolha de um representante para compor o Conselho Nacional de Políticas Culturais - CNPC. Os Fóruns e Colegiados Setoriais têm como um de seus objetivos essenciais subsidiar o CNPC na elaboração e sistematização do Plano Nacional de Cultura, PNC. As diretrizes formuladas por este colegiado serão submetidas aos participantes do Conselho Nacional de Cultura e, uma vez aprovadas, integrarão o Plano Nacional de Cultura. O Plano é um instrumento de planejamento que, se convertido em lei, instruirá as ações dos governos no âmbito da cultura. Não se trata, portanto, de programa governamental, com efeitos transitórios. Por ser uma lei com efeitos duradouros, extrapola o período de vigência de diferentes governos (BATISTA, 2013).

O Plano Nacional de Cultura é um indutor de políticas de Estado. Instrui políticas públicas que, uma vez transformadas em lei, convertem-se em instrumentos de ação e de ampliação de direitos sociais (Figura 02).

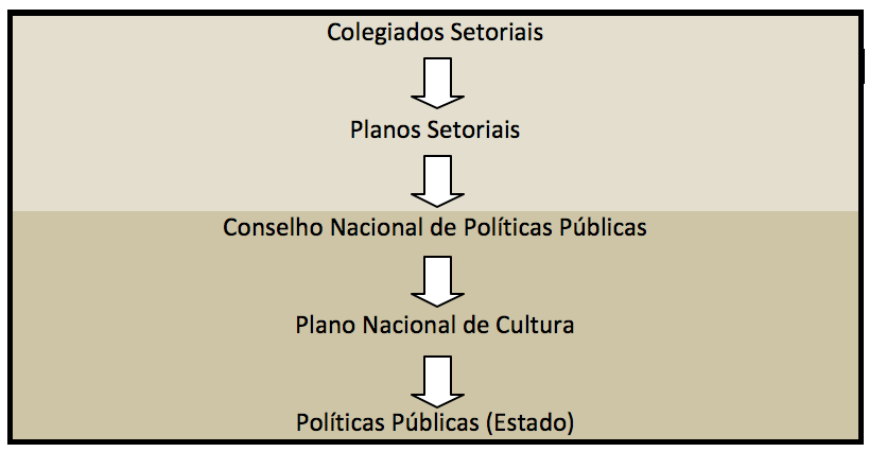

Figura 02: Fluxograma das Instâncias de tramitação das Políticas Públicas.

Dentre os objetivos do Colegiado Setorial de Design, destaca-se a realização de ampla coleta de dados sobre temas específicos, sintonizados com desafios propostos pela Secretaria de Economia Criativa , SEC, com os eixos de discussão adotados para a III Conferencia Nacional de Cultura/ 2013, com a finalidade de produzir análise situacional, precedida de sucinta recuperação histórica e contextualização do design . A partir dessas informações preliminares, o colegiado formulará objetivos norteadores do Plano Setorial de Design, cuja realização está prevista para novembro de 2014. 
Até lá, com o propósito de consubstanciar o caráter democrático do Plano Setorial, várias iniciativas serão desencadeadas para promover a sensibilização, a mobilização, a discussão e a apresentação de proposições alternativas ao Plano elaborado pelo colegiado de design. Entre elas, a participação em eventos, a socialização de informações por meio de diferentes canais de comunicação, a constituição de grupos de trabalho informais, que desembocarão em consulta pública agendada para o período de 30 de julho a 30 de agosto de 2014. Uma vez consolidada a sondagem, o Plano Setorial será submetido à apreciação e à deliberação do Conselho Nacional de Políticas Públicas- CNPC.

(BATISTA, 2013)

O colegiado concretiza os primeiros passos visando à consecução de demandas de estudantes e de profissionais desta área de atividades, entre as quais a regulamentação da profissão de designer.

Atualmente, o Ministério da Cultura congrega 19 setores com especificidades culturais. Destes, 17 já dispõem de colegiados instalados. Sendo que uma dezena destes organismos encontra-se em fase de elaboração de seus planos setoriais, o design inclusive. Estes documentos têm como escopo reunir diferentes segmentos para atingir proposições culturais mais abrangentes, que integrem peculiaridades regionais, que facultem a compreensão das principais demandas setoriais, proporcionando parâmetros técnicos e políticos capazes de viabilizar os objetivos de estratégias e de políticas culturais, entre as quais a democratização e a socialização da cultura.

\section{CONSIDERAÇÕES FINAIS}

“Não tem sentido a memória apenas para guardar o passado.

(...) A tarefa de preservação do patrimônio cultural brasileiro, ao invés de ser uma tarefa de cuidar do passado, é essencialmente uma tarefa de refletir sobre o futuro".

Aloísio Magalhães

Ao encerrar este trabalho, cabe considerar que para refletir sobre o papel do design(er) na discussão, formulação e implantação de políticas públicas culturais, antes de tudo precisamos reiterar que políticas públicas são resultantes das atividades políticas. Portanto, implicam em participação.

Nesse sentido, o aporte de Kim Vicente (2004) sobre o entendimento dos fatores humanos representados pela Escada Humano-tecnológica (ver Figura 01) pode ser uma imagem rica de significados, porque contribui na compreensão da sistêmica e complexa relação dos fatores humano-tecnológicos no contexto mais amplo da sociedade. Sua analogia nos permite visualizar uma imagem que abarca todos os níveis do processo, desde a base até o topo, ou seja, desde os fatores físicos, para então começar a subir em direção aos outros níveis, como o trabalho em equipe, às organizações e os sistemas políticos.

Quando ressalta a estreita relação entre objetos físicos e "objetos políticos" , ele evidencia a importância de compreender os sistemas políticos e como estes afetam o design, ao ampliar (ou restringir) o seu campo de atuação. Portanto, revela como o design(er) precisa estar atento aos sistemas políticos que repercutem diretamente na sua profissão. Vicente (2005) destaca que "nossa compreensão da natureza humana 
no nível político não é tão sofisticada ou tão completa quanto a dos níveis físico e psicológico, porque os fenômenos a serem explicados são muito mais complexos". Talvez aí, resida uma importante chave para compreender a postura refratária do setor ao qual Batista se refere recorrentemente em seu discurso.

E, devido a essa complexidade acerca o nível político, as considerações de Maffei, Mortati e Villari (2012) são oportunas neste trabalho quando destacam que as políticas públicas não devem ser feitas somente por políticos, mas por todos os atores que formam a sociedade, porque práticas colaborativas podem melhorar e apoiar a formulação de políticas em diferentes níveis. O que leva ainda a questão dos movimentos que profissionais e acadêmicos da área têm feito junto ao poder público e privado, suas conquistas e reconhecimento, não só em nível político, mas junto ao grande público. Dentre os três graus de envolvimento na relação dos cidadãos com o governo, desde o mais passivo ao mais ativo: informativo; consultivo; participativo, cabe assinalar que o processo democrático que vem sendo promovido na relação do Estado com a cultura no cenário nacional mais recente apresenta propostas participativas, numa relação recíproca quando o Governo envolve os cidadãos no ciclo de discussão e formulação das políticas, uma vez que são suficientemente competentes para sugerir soluções e contribuir para com o debate.

De nossa parte, reiteramos a fala de Wagner Braga Batista, quando expressa seu desejo de que o Colegiado Setorial de Design, constituído em 2012, tenha composição pluralista, ampla e com reconhecida competência. Porque essas características qualificam o Colegiado a enfrentar um desafio inédito: participar na elaboração de políticas públicas num contexto promissor de expansão da economia brasileira e de avaliação e melhoria dos cursos de "desenho industrial e design", bem como de avanço no processo de regulamentação da profissão (BATISTA, 2012 A).

$\mathrm{Na}$ implantação da III CNC, o fato do Colegiado Setorial de Design ter se constituído um semestre antes da realização da III Conferência Nacional de Cultura/ 2013 é um indicador de amadurecimento e participação do setor. O que corrobora a avaliação de Batista (2010) sobre a articulação do design na II Conferência Nacional de Cultura/2010, ao ponderar que sua representatividade deficitária correspondia ao estágio inicial de um processo em andamento. Então, podemos supor que inicia uma cultura de participação coletiva no/do setor do design em relação a políticas públicas culturais.

Nesta perspectiva, Batista defende a necessidade de integração do design com os setores de arte e da cultura. Integração que começa a ser estimulada pelos órgãos oficiais, como a iniciativa institucional do Ministério da Cultura ao unir três áreas: moda, arquitetura e design a partir de 2010, através da Secretaria de Políticas Culturais.

Em suma, a inserção do design no escopo de políticas públicas possibilita um redimensionamento do setor porque viabiliza intervenções mais férteis, socialmente falando. Assim, amplia-se o campo de atuação do setor, tornando patente a questão que o "mercado é apenas uma das esferas da vida social", e não esgota o campo de atuação do setor. E a cultura não se reduz a suas tendências, constituindo-se como um elemento a ser preservado, (re) conhecido e pesquisado. Enfim, ao discutir as relações do design no âmbito das políticas públicas, cabe evocar o nome de Aloísio Magalhães que, na década de 1970, já levantava questões acerca o patrimônio artístico-cultural e iniciava o design no âmbito das políticas culturais no cenário nacional. E como diz 
Aloísio, a memória não é para guardarmos o passado, mas para refletirmos sobre o futuro. Um design(er) que, no futuro, seja mais participativo.

\section{REFERÊNCIAS}

BATISTA, Wagner Braga. O papel do design na II Conferência Nacional de Cultura. In: Anais do 9 Congresso Brasileiro de Pesquisa e Desenvolvimento em Design. Anhembi Morumbi, São Paulo 2010.

Forum Setorial de Design será realizado em Brasilia. Disponível em: <http://www.ufcg.edu.br/prt_ufcg/assessoria_imprensa/mostra_noticia.php?codigo= 14498> Campina Grande, 2012.

Rumo ao Fórum Setorial de Design. Disponível em: <http:/www.ufcg.edu.br/prt_ufcg/assessoria_imprensa/mostra_noticia.php?codigo=1 3592> Campina Grande, 2012A.

- Colegiado Setorial de Design do Ministério da Cultura, primeiros passos. Disponível em:

http://www.ufcg.edu.br/prt_ufcg/assessoria_imprensa/mostra_noticia.php?codigo=1 5190> Campina Grande, 2013.

CABRALE, Lia. Políticas Culturais no Brasil: balanço e perspectivas. In: III ENECULT, Terceiro Encontro de Estudos Multidisciplinares em Cultura, Faculdade de Comunicação, UFBa, Salvador-Bahia, 2007.

COELHO NETO, José Teixeira, Dicionário crítico de política cultural, São Paulo: 1997.

FALCÃO, Joaquim. A política cultural de Aloísio Magalhães. In: E Triunfo? A questão dos bens culturais no Brasil. Nova Fronteira - Fundação Roberto Marinho: Rio de Janeiro, 1997.

MAFFEI, Stefano; MORTATI, Marzia; VILLARI, Beatrice. Making/Design policies together. 2012

MENEZ, Daniela da Silva. Análise das políticas públicas culturais do RS de 1995 a 2011. Especialização em Gestão Pública UFRGS. 2011.

VICENTE, Kim, The Human Factor: revolutionizing the way people live with technology. Routledge: New York, 2004.

VICENTE, Kim, Homens e Máquinas: como a tecnologia pode revolucionar a vida cotidiana. Ediouro: Rio de Janeiro, 2005. 